\title{
Using CFD to improve the performance of a heat exchanger from a gasifier
}

\author{
Liliana Dumitrescu ${ }^{2 *}$, Edmond Maican ${ }^{1}$, Ioan Pavel $^{2}$, Cătălin Dumitrescu ${ }^{2}$, Iuliana \\ Găgeanu $^{3}$, and Andrei Pătruț ${ }^{4}$ \\ 1’Politehnica" University of Bucharest, Faculty of Biotechnical Systems Engineering, Spl. \\ Independenţei no. 313, Sector 6, Bucharest, 060042, Romania \\ ${ }^{2}$ Hydraulics and Pneumatics Research Institute INOE 2000-IHP, Cuțitul de Argint no. 14, Sector 4, \\ Bucharest, 040558, Romania \\ ${ }^{3}$ National Institute of Research-Development for Machines and Installations designed for Agriculture \\ and Food Industry - INMA, 6 Ion Ionescu de la Brad Blv., sector 1, Bucharest, 013813, Romania \\ ${ }^{4}$ SC CALORIS SA, Şos. Berceni no. 8A, Sector 4, Bucharest, 041914, România
}

\begin{abstract}
In this paper, a Computational Fluid Dynamics (CFD) analysis is performed on a gas-liquid heat exchanger fitted on a gasification equipment. The flow and temperature patterns are preliminary investigated using SolidWorks Flow Simulation software, in order to gain insight into the involved physical processes, and to find the exchanger weak points before being manufactured and tested. The analysed equipment tranfers heat from the flue gasses generated by a gasification system, towards a liquid heat transfer medium. This is subsequently sent to a second liquidliquid heat exchanger used to heat water from a boiler. As a result of the analysis, solutions aiming at performance improvement of the equipment are discussed and proposed.
\end{abstract}

\section{Introduction}

Full exploitation of biomass energy potential is a strategic part of the EU renewable energy policy, as stated within the Directive 2009/28/EC [1]. The emphasis is on supply chains and on a $20 \%$ improvement of the technology efficiency and greenhouse gas (GHG) savings. Unlike wind and solar energy, biomass can be continuously supplied regardless climatic conditions. In terms of heat production, small scale systems are seen as the most effective and viable option in harnessing the locally available biomass, due to transportation cost reduction. Higher efficiency alternatives to simple biomass burning are considered, such as thermo-chemical conversion through gasification, thus avoiding health threats such as relatively high levels of $\mathrm{GHG}$ emmissions $\left(\mathrm{N}_{2} \mathrm{O}\right.$ and $\left.\mathrm{CH}_{4}\right)$, polycyclic aromatic hydrocarbons, or particulate matter [2, 3].

An important aspect of these type of equipment is the way heat is recovered from the flue gas. Depending on flue gas parameters, gasification system geometry, ease of maintenance, fluids, and performance requirements, various types of heat exchangers have been studied and used. The performance of heat exchangers is influenced over time in a

\footnotetext{
* Corresponding author: lilianad.ihp@,fluidas.ro
} 
negative way, mostly due to contaminants that can build up deposit layers onto the exchanger walls (tars, particulates, sulfur, and others), thus affecting heat transfer and also reducing the section of the flow area $[4,5]$. Currently, computational fluid dynamics (CFD) is an usual tool that is used in performance assessment and improvement.

An optimized heat exchanger design can perform better for a longer periods of time, thus reducing the number of maintenance steps. This paper presents the use of CFD to evaluate the performance of a heat exchanger from an existing gasification system and then to assess a modified and improved design, and also to propose solutions for further improvements.

\section{Methods}

The initial design of the heat exchanger is presented in Figure $1 b$. The total heat exchange surface of the five tubes is $0.25 \mathrm{~m}^{2}$. Each tube has an inner diameter of $71 \mathrm{~mm}$ and a height of $225 \mathrm{~mm}$. Heat is also transfered through the top and bottom walls of the exchanger, which translates into a total surface (including the tubes) of $0.31 \mathrm{~m}^{2}$. In Flow Simulation, inlets and outlets for flue gas and water should be represented as solid surfaces (Figure $1 b$ ).

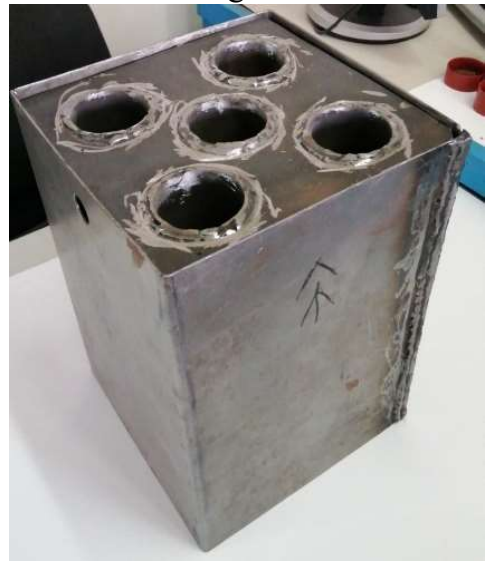

a)

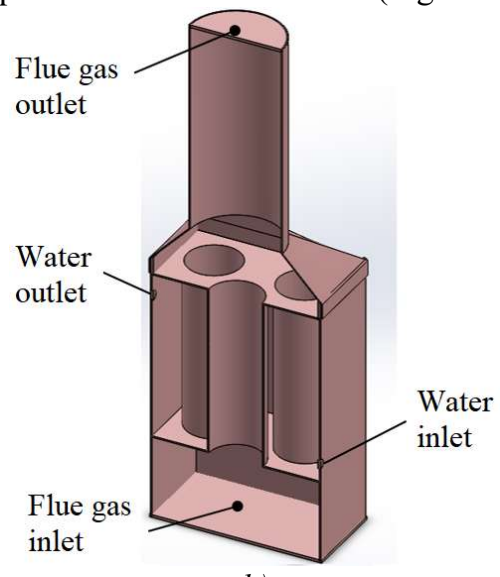

b)

Fig. 1 - Initial design of the heat exchanger: (a) before mounting into the evacuation assembly; (b) heat exchanger and flue gas admission and evacuation assembly (section view of a simplified CAD model for fluid dynamics simulation)

Based both on experimental data performed previously onto the existing gasification system, and on the requirements regarding the working regime of the entire heating assembly, the following initial data has been provided in the preprocessing step:

- Average temperature of gas at the inlet: $250{ }^{\circ} \mathrm{C}$;

- Total gas flow at the inlet: $14.6 \mathrm{l} / \mathrm{s}$;

- Water flow rate: $6 \mathrm{l} / \mathrm{min}$ and $3 \mathrm{l} / \mathrm{min}$ (both situations were simulated);

- Water temperature at the inlet: $20.05^{\circ} \mathrm{C}$;

- Water volume in the initial heat exchanger design: $5.9 l$;

- Heat transfer coefficient: in order to consider heat losses through the exterior walls of the equipment and to assess the heat exchanger efficiency, the option of heat conduction in solids was activated. According to literature, for steel and gas-liquid exchangers, heat transfer coefficient ranges between $15 \ldots 70 \mathrm{~W} /\left(\mathrm{m}^{2} \mathrm{~K}\right)$ for liquid outside tubes and gas at atmospheric pressure inside tubes [6, 7]; simulations were made starting at $10 \mathrm{~W} /\left(\mathrm{m}^{2} \mathrm{~K}\right)$, than a value of $20 \mathrm{~W} /\left(\mathrm{m}^{2} \mathrm{~K}\right)$ was considered; these low values take into consideration the contaminant deposits that form onto the heat exchanger walls during operation. 


\section{Results and discussion}

As mentioned earlier, the simulation was performed for two different water flow rates, namely $6 \mathrm{l} / \mathrm{min}$ and $3 \mathrm{l} / \mathrm{min}$. These values were selected in accordance with the maximum (6 l/min) and minimum $(2.76 \mathrm{l} / \mathrm{min}$ ) flow rates of the pump that recirculates the water within the closed-circuit where the heat exchanger is installed. As expected, results were better for the lower flow rate value, but the overall average water temperature at the outlet can be considered unsatisfactory: just $24.7^{\circ} \mathrm{C}$. Figure 2 shows that one parameter that influence this result is the location of the water outlet under the layers of hot water.
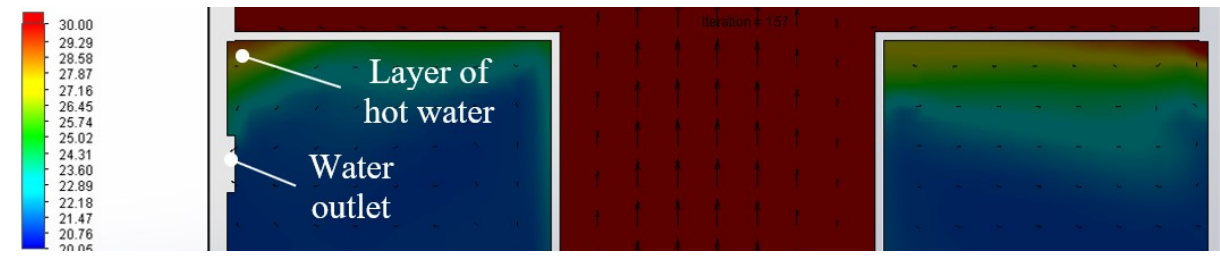

Fig. 2 - The water outlet is placed well below the layer of hot water

The other parameters that affected the heat exchanger performance are:

- Low water volume in the heat exchanger; considering a flow of $3 \mathrm{l} / \mathrm{min}$, the entire volume of cold water is recirculated in less than two minutes;

- The exchanger tubes; their diameter is too large and they are too short in relation to the overall dimensions of the exchanger.

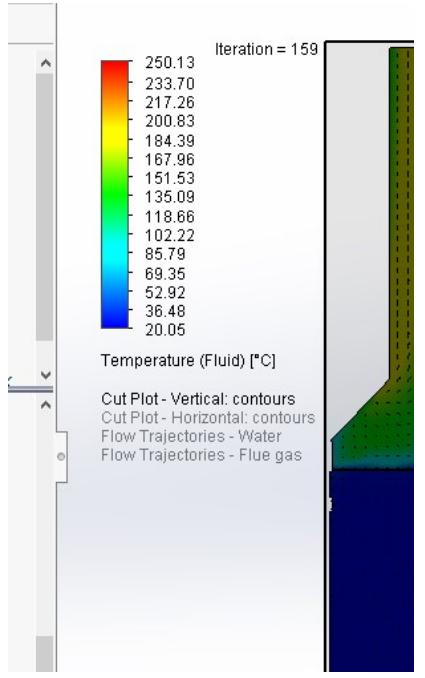

(a)

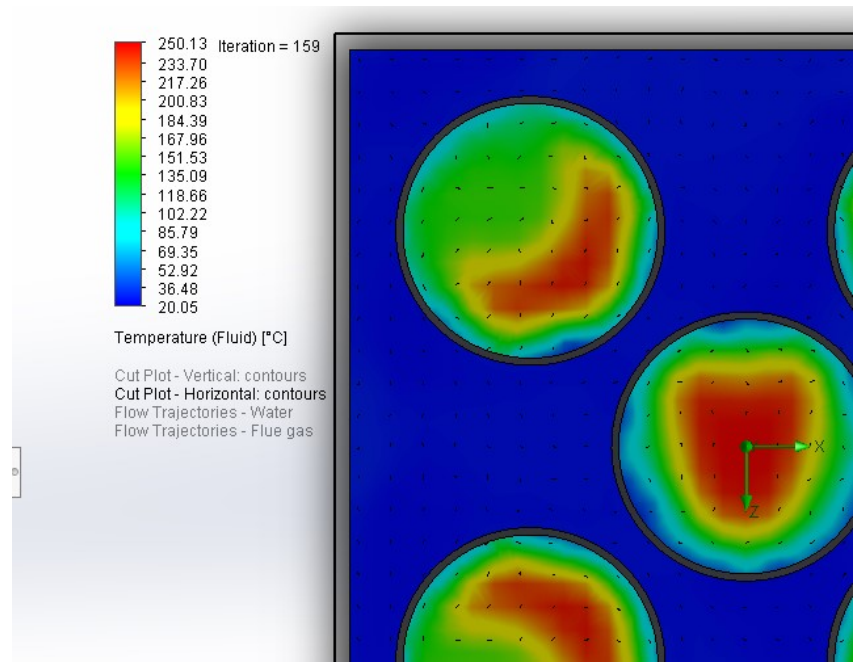

(b)

Fig. 3 - Flue gas temperature: a) vertical section view; b) cross-section at top of the exchanger tubes

Due to these two design parameters, flue gases leave the exchanger relatively quickly, without having enough time to efficiently transfer heat to the liquid thermal agent (Figure 3). The average temperature of the gases at the flue-gas outlet is about $180{ }^{\circ} \mathrm{C}$, and the average temperature of the walls is $114{ }^{\circ} \mathrm{C}$, meaning large heat losses through the walls. The average flue gas temperature at the outlet of the central tube is high (about $230^{\circ} \mathrm{C}$ ). To improve the performance of the heat exchanger, the following changes were made to the original design:

- The 5 pipes with an inner diameter of $70 \mathrm{~mm}$ were replaced with 9 cold drawn seamless pipes with an outer diameter of $48.3 \mathrm{~mm}$ (wall thickness: $2.93 \mathrm{~mm}$, inner diameter of 
approximately $42.5 \mathrm{~mm}$ ); keeping the cross section of the exchanger unchanged will result in a more compact design, characterized by a better heat transfer performance [8]

- The height of the heat exchanger was increased from $225 \mathrm{~mm}$ to $500 \mathrm{~mm}$.

No change was made to the water outlet position, in order to asses the performance only due to changing the pipes number and dimensions. Simulation conditions have also been kept unchanged in terms of total gas and water flow rates and inlet temperatures. Heat transfer coefficient has been established to $20 \mathrm{~W} /\left(\mathrm{m}^{2} \mathrm{~K}\right)$. Figure 4 shows a longitudinal section of the new design of the heat exchanger.
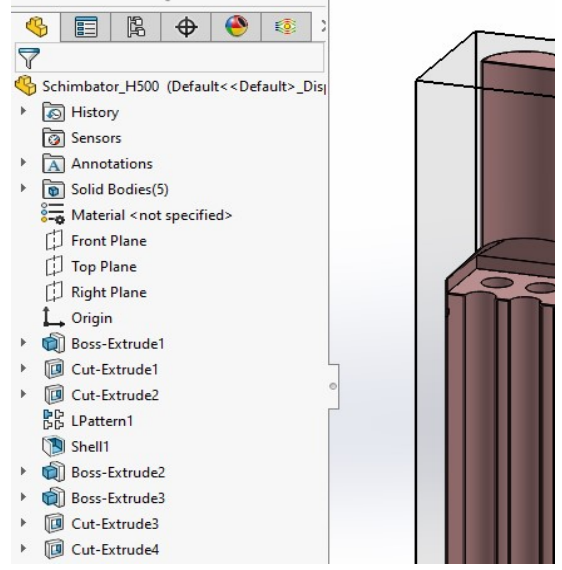

Fig. 4 - New heat exchanger design: 9 cold drawn seamless pipes $(\Phi=48.3 \mathrm{~mm})$

Under the above conditions, the average water temperature at the outlet of the modified heat exchanger is $65.5^{\circ} \mathrm{C}$ (Figure 5), and the average flue gas temperature at outlet is $155^{\circ} \mathrm{C}$.

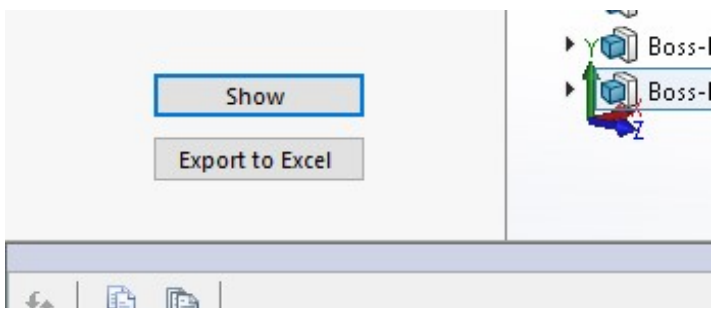

Fig. 5 - Water average temperature at the outlet increased to $65.5^{\circ} \mathrm{C}$ in case of the new design

The layer of water above the outlet is thicker than in the previous design and has an average temperature in the range of the boiling point. The water outlet partialy captures this layer of hot water (Figure 6).
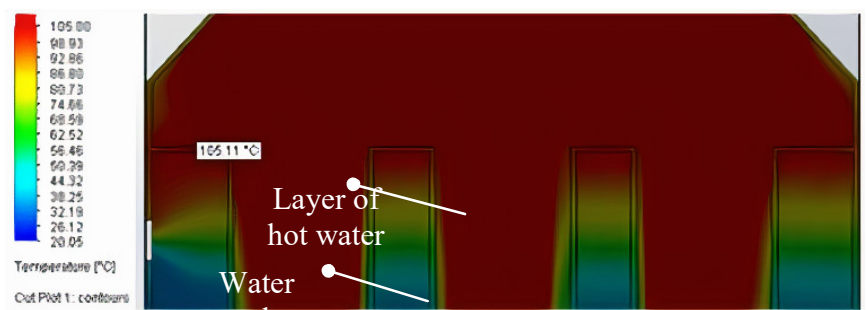

Fig. 6 - The layer of water above the outlet has a temperature in the range of the boiling point; placing the outlet higher will capture a higher volumic flow of high temperature water

This new design clearly shows performance improvement when compared to the original design. However, the overall performance can be further optimized by means of the following design changes: 
- Insulation of the exterior walls with ceramic fiber wool (resistant to high temperatures), to limit heat loss due to heat transfer to the ambient environment by conduction through the walls. The entire housing should be insulated, except the chimney. In Figure 7, one can notice that the temperature of the gas near the walls (before entering the heat exchanger) drops just below $100^{\circ} \mathrm{C}$, due to large heat losses through the walls.

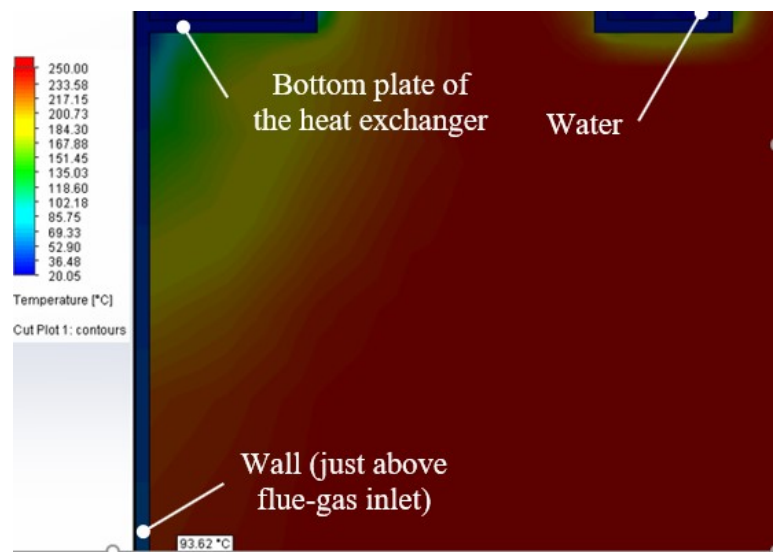

Fig. 7 - Flue gas temperature close to the exterior walls drops below $100{ }^{\circ} \mathrm{C}$ just before entering the heat exchanger, due to high heat conduction through the non-isolated exterior walls

- According to Figure 6, the water outlet takes a low volumetric flow from the upper layer of high temperature water. In order to take over a higher flow from this layer, one of the following three design changes should be adopted:

a) Moving the water outlet with at least $15 \mathrm{~mm}$ above;

b) The above design change can prove difficult due to the fact that the distance between the water outlet and the top plate of the exchanger is already relatively small (this area is "sensitive" due to existing welding seams); therefore, in an alternative design change, the water outlet position remains unchanged, but the top plate of the heat exchanger is inclined at an angle of $10^{\circ}$ relative to the horizontal (Figure 8), to facilitate the formation of a thicker layer of hot water in the area of the outlet.

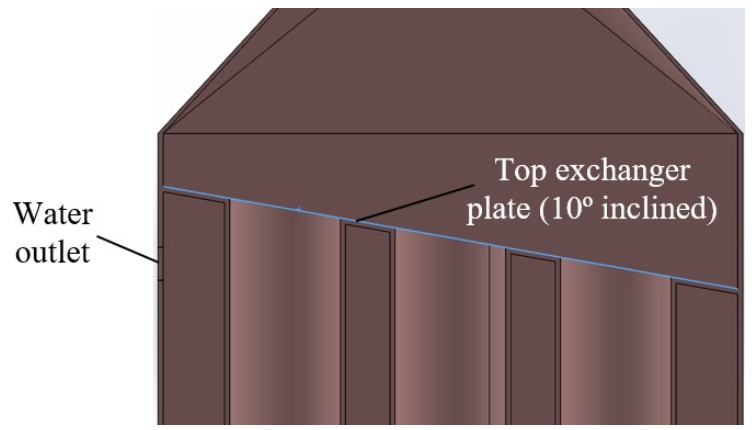

Fig. 8 - Inclining the top plate of the heat exchanger facilitates the formation of a thicker layer of hot water in the area of the water outlet

c) Adoption of a combined solution, which consists in moving the water outlet higher with a distance less than the previously proposed $(8 \mathrm{~mm}$, instead of $15 \mathrm{~mm})$ in order to avoid the nearby welding seams, together with the placement of the upper wall at an angle of $10^{\circ}$ relative to the horizontal. 
- Pressurizing the water circuit to prevent boiling at the top of the heat exchanger. A 3 bar pressure is recommended, with safety valve and expansion vessel.

\section{Conclusions}

After the evaluation of the original heat exchanger design, a $24.7^{\circ} \mathrm{C}$ overall average water temperature at the outlet was determined. The average temperature of the flue-gas at the outlet was about $180^{\circ} \mathrm{C}$, and at the outlet of the central tube was about $230^{\circ} \mathrm{C}$. The average temperature of the walls was $114^{\circ} \mathrm{C}$, meaning important heat losses through the walls.

An improved design with 9 cold drawn seamless pipes and a height of the heat exchanger of $500 \mathrm{~mm}$, was proposed and tested. The average water temperature at the outlet increased to $65.5^{\circ} \mathrm{C}$, and the average flue gas temperature at outlet decreased to $155^{\circ} \mathrm{C}$. Based on flow and temperature patterns, new improvements are proposed to further increase its performance: insulation of the exterior walls to limit heat loss through the walls; moving the water outlet $15 \mathrm{~mm}$ higher to catch the top high temperature water layer; inclining the exchanger top plate with $10^{\circ}$ to increase the hot water layer thickness in the outlet area; pressurizing the water circuit to prevent boiling. Following the adoption of the above design changes, a new CFD analysis will be performed to asses the heat exchanger increase in performance.

This work was carried out under the project Creating a high level proficiency nucleus in the field of increasing renewable energy conversion efficiency and energy independence by using combined resources, project acronym: CONVENER, Financial agreement no. 37/02.09.2016, funded by the European Regional Development Fund through the Operational Program Competitiveness 2014-2020, Priority Axis 1: Research, technological development and innovation (RD\&I) to support economic competitiveness and business development, Action 1.1.4 - Attracting high-level personnel from abroad in order to enhance the R\&D capacity.

\section{References}

1. EU Parliament, Directive 2009/28/EC of the European Parliament and of the Council on the promotion of the use of energy from renewable sources, Official Journal of the European Union, Brussels (2009)

2. R. Devesa-Rey, X. Vecino, J.L. Varela-Alende, M.T. Barral, J.M. Cruz, A.B. Moldes, Valorization of winery waste vs. the costs of not recycling, Waste Management, Vol. 31, pp. 2327-2335, ISSN 0956-053X (2011)

3. E. Maican, E. Murad, G. Cican, I.C. Duţu, Analysis of a Top Lit Updraft Gasification System Designed for Greenhouses and Hothouses, Proceedings of the 16-th International Multidisciplinary Scientific Geoconferences (SGEM), vol. Renewable Energy Sources and Clean Technologies, Albena, Bulgaria, pp. 107-114, ISSN 1314-2704 (2016)

4. H. Lu, T. Ma, L. Lu, Deposition characteristics of particles in inclined heat exchange channel with surface ribs, International Journal of Heat and Mass Transfer, Vol. 161, 120289, ISSN 0017-9310 (2020)

5. Z. Zheng, W. Yang, P. Yu, Y. Cai, H. Zhou, S. K. Boon, P. Subbaiah, Simulating growth of ash deposit in boiler heat exchanger tube based on CFD dynamic mesh technique, Fuel, Vol. 259, 116083, ISSN 0016-2361 (2020)

6. J. Primo, Shell and Tube Heat Exchangers Basic Calculations, PDH Online Course M371, PDH Center, 5272 Meadow Estates Drive, Fairfax, pg. 12/32 (2012)

7. Engineering ToolBox, Heat Exchanger Heat Transfer Coefficients, Available at: https://www.engineeringtoolbox.com/heat-transfer-coefficients-exchangers-d_450.html (2003) 
8. M. El-Shafie, M. Khalil Bassiouny, S. Kambara, S. M. El-Behery, A.A. Hussien, Design of a heat recovery unit using exhaust gases for energy savings in an absorption air conditioning unit, Applied Thermal Engineering, Vol. 194, 117031, ISSN 13594311 (2021) 